\title{
Fabrication and characterization of free-standing thick-film piezoelectric cantilevers for energy harvesting
}

\author{
Swee-Leong Kok, Neil M White and Nick R Harris \\ School of Electronics and Computer Science, University of Southampton, UK \\ E-mail: slk05r@ecs.soton.ac.uk
}

Received 1 May 2009, in final form 14 September 2009

Published 26 October 2009

Online at stacks.iop.org/MST/20/124010

\begin{abstract}
Research into energy harvesting from ambient vibration sources has attracted great interest over the last few years, largely as a result of advances in the areas of wireless technology and low-power electronics. One of the mechanisms for converting mechanical vibration to electrical energy is the use of piezoelectric materials, typically operating as a cantilever in a bending mode, which generate a voltage across the electrodes when they are stressed. Typically, the piezoelectric materials are deposited on a non-electro-active substrate and are physically clamped at one end to a rigid base. The presence of the substrate does not contribute directly to the electrical output, but merely serves as a mechanical supporting platform, which can pose difficulties for integration with other microelectronic devices. The aim of this paper is to describe a novel thick-film free-standing cantilever structure that does not use a supporting platform and has the advantage of minimizing the movement constraints on the piezoelectric material, thereby maximizing the electrical output power. Two configurations of the composite cantilever structure were investigated: unimorph and multimorph. A unimorph consists of a pair of silver/palladium $(\mathrm{Ag} / \mathrm{Pd})$ electrodes sandwiching a laminar layer of lead zirconate titanate (PZT). A mulitmorph is an extended version of the unimorph with two pairs of $\mathrm{Ag} / \mathrm{Pd}$ electrodes and three laminar sections of PZT.
\end{abstract}

Keywords: thick-film technology, PZT, microgenerator, low level vibrations, free-standing structure, multimorph cantilever

(Some figures in this article are in colour only in the electronic version)

\section{Introduction}

Cantilevers are simple geometric structures, which induce stress on piezoelectric materials when used in a bending mode of operation. The structures usually consist of a supporting platform, with one end clamped to a rigid base and the other end free to move. Piezoelectric materials are deposited on either one side (unimorph) or both sides (bimorph) of the platform in such a way that the films can be stressed to generate charges as a result of the $d_{31}$ mode of the piezoelectric effect.

The supporting platforms, on which the functional materials are printed, are not electrically active but act as a mechanical support to the whole structure. These are often materials such as stainless steel, aluminium plate or micromachined silicon, depending on the fabrication processes and the requirements on physical size. One of the earliest examples of thick-film energy harvesters, based on cantilever configuration, is described by Glynne-Jones et al [1]. The harvester was fabricated by screen-printing a layer of PZT (type-5H) with a thickness of $70 \mu \mathrm{m}$ on both sides of a stainless steel beam of length $23 \mathrm{~mm}$ and thickness $100 \mu \mathrm{m}$, to form a bimorph cantilever. The device had a resonant frequency of $80.1 \mathrm{~Hz}$ and produced up to $3 \mu \mathrm{W}$ of electrical power when driving into an optimum resistive load of $333 \mathrm{k} \Omega$.

Another example, which uses stainless steel as the supporting platform, is described by Roundy et al [2]. The structure has a bimorph configuration and consisted of two 
sheets of PZT (type-5A) attached to both sides of the steel beam, which acts as the centre shim. The structure has an overall size of about $1 \mathrm{~cm}^{3}$, including a proof mass that is attached at the tip of the cantilever. When excited at $100 \mathrm{~Hz}$ with an input acceleration of $2.25 \mathrm{~m} \mathrm{~s}^{-2}$, it produced an output power of about $70 \mu \mathrm{W}$ when driving into a resistive load of $200 \mathrm{k} \Omega$. An improved version of the prototype was developed and comprised a cantilever (length $28 \mathrm{~mm}$, width $3.2 \mathrm{~mm}$ and PZT thickness of $0.28 \mathrm{~mm}$ ), a proof mass (length $17 \mathrm{~mm}$, width $3.6 \mathrm{~mm}$ and height $7.7 \mathrm{~mm}$ ) and was found to generate a maximum power of $375 \mu \mathrm{W}$ when excited at its resonant frequency of $120 \mathrm{~Hz}$ for an input acceleration of $2.5 \mathrm{~m} \mathrm{~s}^{-2}$ [3].

Sodano et al [4] have used aluminium plates of thickness $63.5 \mu \mathrm{m}$ as the supporting platforms and have attached piezoceramic PZT and macro-fibre composite (MFC) samples in order to compare the efficiency of the active materials, and also the time taken, for charging batteries. The PZT sample was PSI-5H4E piezoceramic from Piezo Systems Inc. having a length of $62.5 \mathrm{~mm}$ and a width of $60.32 \mathrm{~mm}$, while the MFC sample was a thin PZT fibre film developed by NASA. The fibres were embedded in a Kapton film of dimensions $82.55 \times$ $57.15 \mathrm{~mm}$ and having an interdigitated electrode (IDE) pattern, which allows the device to be operated in the $d_{33}$ piezoelectric mode rather than the $d_{31}$ mode, which has a lower magnitude. From the experiments, they concluded that the PZT piezoceramic performed better than the MFC sample. Despite the higher value of $d_{33}$ compared to $d_{31}$, the electrical current produced by the MFC sample was very small and not suitable for power harvesting. The piezoceramic PZT sample, operating at its resonant frequency of $50 \mathrm{~Hz}$, was capable of charging a battery, of capacity $80 \mathrm{~mA} \mathrm{~h}$ at $1.2 \mathrm{~V}$, in a time of $1.2 \mathrm{~h}$.

An example of a device that uses silicon as the supporting platform is described by Jeon et al [5]. The cantilever, with dimensions of $170 \mu \mathrm{m} \times 260 \mu \mathrm{m}$, had a fundamental resonant frequency of $13.9 \mathrm{kHz}$ and was able to generate an electrical power of $1 \mu \mathrm{W}$ at a base displacement of $14 \mathrm{~nm}$, when driving into a resistive load of 5.2 $\mathrm{M} \Omega$. There are many other micromachined silicon cantilevers described in the literature [6-8], although most of these are used in biochemical detection applications rather than energy harvesting.

A free-standing structure is one that stands alone (or on its own foundation) and is free from external support or attachment to a non-electro-active platform. One of the advantages of free-standing thick-film structures is their ability to provide a support structure upon which other sensing materials can be deposited. Such structures are threedimensional micromechanical structures and are analogous to silicon micro-machined MEMS [9]. The main difference is that free-standing thick-film structures are formed without the need for a supporting platforms, which are passive mechanical elements that do not directly contribute to the generation of electrical energy. It is therefore desirable for them to be thin and flexible.

Free-standing thick-film devices are multilayered structures comprising only screen-printed piezoelectric materials and electrodes. Their mechanical (e.g. $Q$-factor and elastic constants) and electrical properties (piezoelectric coefficients and coupling factor) can be measured in the absence of the supporting platform. The piezoelectric charge constant, $d_{33}$, can be directly measured using the Berlincourt method, rather than being inferred indirectly as with measurements on clamped films [10, 11].

Free-standing thick-film structures can be fabricated using mass-production methods and do not need to be assembled manually, unlike some other devices described in the literature $[1,2,4]$. It is therefore possible to create quite complex structures with a series of relatively simple fabrication steps. They can also be integrated with other thick-film layers and microelectronic components, thereby offering an interesting alternative to micromachined MEMS.

Circular membranes (a form of free-standing structure), for use as a pressure sensor and fabricated with thick-film technology, were first described by Stecher over 20 years ago [12]. Since then, however, there has been very little concerted effort to apply thick-film technology for fabricating free-standing piezoelectric transducers. One reason for this is that piezoceramics are generally considered to be too fragile to form robust, free-standing structures.

The aim of this paper is to fabricate robust and miniature $\left(<5 \mathrm{~cm}^{3}\right)$ thick-film piezoelectric energy harvesters, in the form of free-standing cantilevers. The adopted fabrication technique results in the formation of a beam by a process of burning out a sacrificial layer at elevated temperatures. The process does not involve any form of chemical processing, thereby offering an environmental advantage over some competing technologies. Screen-printed lead zirconate titanate (PZT) pastes were used, as the active piezoelectric layer and thick-film carbon pastes acted as the sacrificial layer. The piezoelectric cantilevers need to be polarized after fabrication to enhance their piezoelectric activity.

Bulk piezoelectric materials can be measured with either static or dynamic measurement methods. The measurement of thick-film piezoelectrics, however, is not straightforward because the films are attached to a substrate, the effect of which is to introduce a boundary condition on the active material. The longitudinal piezoelectric charge coefficient, $d_{33}$, cannot therefore be measured directly because of the influence of additional electrical charge produced as a result of the transverse piezoelectric, $d_{31}$, effect. The properties of thickfilm piezoelectric materials are therefore inferred accounting for the measurement errors [11]. Free-standing unimorph structures, with a laminar layer of PZT sandwiched between upper and lower electrodes can serve as a characterization tool, to investigate the mechanical and electrical properties of piezoelectric materials.

This paper also discusses a multimorph structure, which aims to improve the electrical output power compared to the unimorph. The multimorph comprises three layers of piezoelectric material having equal thicknesses of about $40 \mu \mathrm{m}$ each and separated by electrodes, together with an outer layer, resulting in a total number of four electrodes.

\section{Free-standing cantilever designs}

A free-standing unimorph cantilever structure with upper and lower electrodes bonded together with a PZT layer and rigidly 


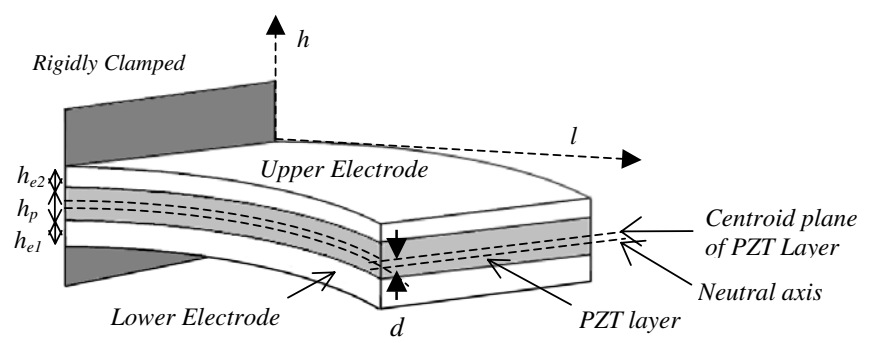

Figure 1. A schematic diagram of a free-standing cantilever structure.

clamped at one end is illustrated in figure 1. The cantilever is free to move at the opposite end when operating in a bending mode so that the PZT material is stressed to produce electrical output voltage. The magnitude of the output voltage depends on the distance between the centroid of the PZT layer and the neutral axis of the material $d$.

A bending cantilever is subjected to tensile and compressive stresses that are proportional to the distance above and below the neutral axis, respectively. There is no resultant stress, $\sigma$, acting on the neutral axis over the cross-section area, $A$, and since the elastic modulus, $E$, and the curvature of the bending cantilever, $\kappa$, are not zero, the integral of the distance from the neutral axis over the cross-sectional area can be written as

$$
\int_{A} \sigma \mathrm{d} A=-\int_{A} E \kappa h \mathrm{~d} A=\int_{A} h \mathrm{~d} A=0 .
$$

The composite beam can be analysed with the transformedsection method [13], where the cross-section of a composite beam is transformed into an equivalent cross-section of an imaginary beam that is composed of only one material with an elastic modular ratio

$$
n_{E}=\frac{E_{e}}{E_{p}}
$$

where $E_{e}$ is the elastic modulus of the electrode layer and $E_{p}$ is the elastic modulus of the PZT layer. Therefore, the distance from the centroid of the PZT layer to the neutral axis of a composite structure with thickness of PZT, $h_{p}$, lower electrode, $h_{e 1}$, and upper electrode, $h_{e 2}$, is

$$
d=\frac{1}{2} h_{p}-\frac{h_{p}^{2}+n_{E}\left(h_{e 1}^{2}-h_{e 2}^{2}+2 h_{p} h_{e 1}\right)}{2\left\{h_{p}+n_{E}\left(h_{e 2}+h_{e 1}\right)\right\}} .
$$

The transverse natural frequency of the composite cantilever with a length, $l_{b}$, larger than its thickness, $h_{b},(l>50 h)$ can be derived from the Bernoulli-Euler beam equation as [14]

$$
f_{i}=\frac{v_{i}^{2}}{2 \pi l_{b}^{2}} \sqrt{\frac{D}{m_{w}}}
$$

where $v_{i}$ is a coefficient related to boundary conditions (and has a value of 1.875 for the fundamental resonant mode), $m_{w}$ is the mass per unit area of the cantilever and $D$ is the bending modulus per unit width given by [15]

$$
D=\sum_{i=1}^{n} E_{i} \int\left(h-h_{N}\right) \mathrm{d} h .
$$

To estimate the natural frequency of the composite unimorph cantilever, the thicknesses of the electrodes are assumed to be symmetric; therefore, the neutral axis is coincident with the centroid of the PZT layer and the bending modulus per unit width of the structure is

$$
D_{\text {unimorph }}=\frac{1}{12} E_{p} h_{p}^{3}+\frac{2}{3} E_{e}\left(h_{e}^{3}+\frac{3}{4} h_{p}^{2} h_{e}+\frac{3}{2} h_{p} h_{e}^{2}\right) .
$$

Assuming that the lengths of the piezoelectric and electrodes are similar (i.e. equal to $l_{b}$ ) and the thickness of the upper and lower electrodes is $h_{e}$, therefore the mass per unit area of the cantilever for a unimorph is

$$
m_{w}=\rho_{p} h_{p}+2 \rho_{e} h_{e}
$$

Substituting equations (6) and (7) into (4) gives the fundamental natural frequency

$$
f_{N}=\frac{0.1615}{l_{b}^{2}} \sqrt{\frac{E_{p} h_{p}^{3}+8 E_{e}\left(h_{e}^{3}+\frac{3}{4} h_{p}^{2} h_{e}+\frac{3}{2} h_{p} h_{e}^{2}\right)}{\rho_{p} h_{p}+2 \rho_{e} h_{e}}} .
$$

Ideally, a cantilever structure with a low natural frequency is desirable for a miniature, integrated system. As the size scales down, however, the resonant frequency scales up, and hence an additional proof mass is needed at the end of the cantilever. The natural frequency for a cantilever with proof mass, $f_{M}$, can be obtained by comparing the natural frequency of a cantilever without proof mass as

$$
f_{M}=f_{N} \sqrt{\frac{m_{\mathrm{eff}}}{m_{\mathrm{eff}}+M_{m}}}
$$

where $M_{m}$ is the additional proof mass and $m_{\mathrm{eff}}$ is the effective mass at the tip of the cantilever, which is given by [14]

$$
m_{\text {eff }}=0.236 m_{b}
$$

where $m_{b}$ is the total mass of the composite cantilever structure.

The output voltage of a piezoelectric cantilever can be estimated with the model developed by Roundy et al [3]. The complex equation for the output voltage of a piezoelectric cantilever when excited to its resonant frequency $\omega_{r}$ is

$$
V=\frac{3}{4} \frac{\mathrm{j} E_{T} d_{31} h_{p} d}{\varepsilon l_{b}^{2}\left\{\zeta_{T} \omega_{r}^{2}-\mathrm{j}\left[\frac{\omega_{r}^{2} k_{31}^{2}}{2}+\frac{\zeta_{T} \omega_{r}}{R C_{p}}\right]\right\}} a_{\text {in }}
$$

where $a_{\text {in }}$ is the base input acceleration, $\varepsilon$ is dielectric constant of the piezoelectric material, $\zeta_{T}$ is the total damping ratio (the sum of electrical and mechanical damping ratio), $C_{P}$ is the capacitance of the piezoelectric material and $E_{T}$ is the elastic modulus of the composite structure. As the total stress in the composite structure is the sum of the stresses in the PZT layer and the electrode layer multiplied by their relative cross-sectional areas, therefore the total elastic modulus is

$$
E_{T}=\left(1-A_{p}\right) E_{e}+A_{p} E_{p}
$$

where $A_{p}$ is the cross-sectional area of the PZT layer.

Although the model is somewhat oversimplified, it does give a reasonably good approximation for the voltage generated and will be used to compare with the experimental results in this work. The electrical output power is calculated using the expression $P=|V|^{2} / 2 R$. 


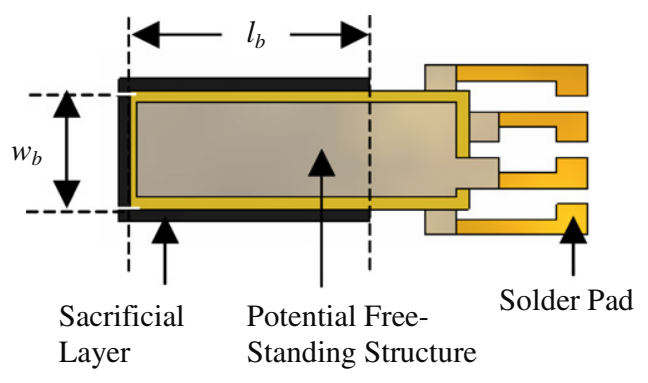

Figure 2. A free-standing cantilever structure design layout.

\section{Processing technique for thick-film devices}

A three-dimensional thick-film structure consists of twodimensional films printed in such a way that some areas are rigidly adhered to the substrate at the base of the structure. The other layers of the device are printed over a sacrificial layer, which will assist in the formation of the freestanding structure as shown in figure 2. Autodesk Inventor (www.autodesk.co.uk) was used to design the structure. Each layer of the design was converted separately into a suitable photo-plotter format that can be translated into a patterned thick-film screen.

Piezoelectric thick-film fabrication steps are typically undertaken sequentially, starting from the paste formulation and screen-printing, followed by drying, co-firing and finally polarization [9]. The films are required to have uniform thickness, be crack-free, have high density, excellent reproducibility and have overall good piezoelectric performance.

The key ingredient for piezoelectric pastes is the PZT (Pz29 Ferroperm Piezoceramics) powder. The PZT powder is sintered at a high temperature $\left(>800{ }^{\circ} \mathrm{C}\right)$ in order to produce a fired, composite piezoelectric film. Lead borosilicate, in the form of a powdered glass frit, was used as the permanent binder. During the co-firing process, the glass melts and binds the PZT particles together to form a solid composite film. At room temperature, the films are very robust and firmly adhered to the substrate.

The presence of the glass modifies the mechanical properties as well as the piezoelectric properties of the film, compared to those of the bulk. Therefore, it is important to mix PZT powder and glass frit in the correct proportion. For example, if the percentage of glass frit is too high, this will reduce the PZT powder loading and reduce the overall piezoelectric activity. Temporary binders (such as pine oil or terpineol) are also present in the paste. They act as an organic vehicle and give the paste thixotropic properties, which allow it to pass easily through the screen in the printing process, but remains firm during the drying process. This is eventually dispersed during the co-firing stage [16].

Silver/palladium $(\mathrm{Ag} / \mathrm{Pd})$ pastes were used as the electrode layer. $\mathrm{Ag} / \mathrm{Pd}$ is also used as the supportive element for the fragile ceramic layer. $\mathrm{Ag} / \mathrm{Pd}$ has been observed to physically curl after co-firing because of its higher thermal expansion coefficient compared to that of the piezoceramic. This effect is shown in figure $3(a)$. It has been established that

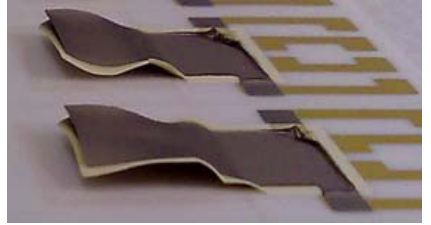

(a)

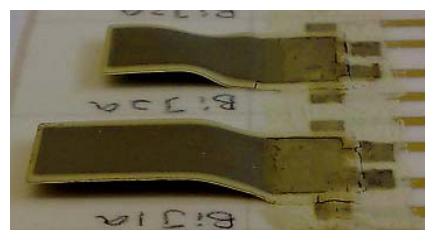

(b)
Figure 3. Photographs of free-standing structures with (a) delaminated electrodes and $(b)$ smoothly matched electrode-ceramic composite.

covering the $\mathrm{Ag} / \mathrm{Pd}$ electrode with a layer of material with lower thermal expansion coefficient reduces this problem. In our case, we printed an additional layer of PZT, of thickness $10 \mu \mathrm{m}$, as non-active layers on both lower and upper electrodes. This resulted in an improved version of the cantilever structure as shown in figure $3(b)$.

The non-active PZT layers are thin and have uniform thickness on both sides of the structure so as not to influence the performance of the device. The position of the neutral axis of the cantilever structure was adjusted by varying the thickness of the upper and lower electrodes, as describe by equation (3).

A carbon paste, similar to that described by Birol et al [17] for the purpose of producing low-temperature co-fired ceramic (LTCC) technology, was used as the sacrificial layer for the free-standing structures. Graphite was chosen because it can be fully burnt out in air at temperatures above $800{ }^{\circ} \mathrm{C}$ and is therefore compatible with the piezoceramic sintering temperature.

Instead of co-firing the layers in a nitrogen atmosphere to allow the piezoceramics to sinter (before the sacrificial layer is burnt off in air) as suggested by Stecher [12], the multilayer composite structure of $\mathrm{Ag} / \mathrm{Pd}$ electrodes, PZT and carbon sacrificial layer were co-fired together in air at a temperature of $850{ }^{\circ} \mathrm{C}$, at which point the piezoceramics sintered and, at the same time, the carbon sacrificial layer is burnt out to release a free-standing structure. The final step of the fabrication process is polarization, which requires an electric field strength of $5 \mathrm{MV} \mathrm{m}^{-1}$ in the thickness direction between the two outer electrodes. The electric field is continuously applied to the materials for $30 \mathrm{~min}$ at a temperature of $200{ }^{\circ} \mathrm{C}$ and is removed once the material has cooled down to room temperature, resulting in permanent polarization of the PZT layers. Figure 4 shows the thick-film fabrication steps of the proposed sacrificial layer technique.

Multilayer, composite free-standing structures were formed owing to the presence of residual stresses within the two materials because of the different thermal expansion coefficients. The resulting beams were non-planar as shown in figure 5. The direction of the bend depends on the arrangement of the layers between the piezoceramics and conductors. Figure 5(a) shows free-standing structures with PZT as the upper layer and $\mathrm{Ag} / \mathrm{Pd}$ as the lower layer, while figure 5(b) shows the arrangement in the other way round. After firing, the beams were found to shrink by about $10 \%$ from their original (pre-fired) dimensions. 
Table 1. Dimensions (mm) of the samples shown in figure 6.

\begin{tabular}{lllllll}
\hline & \multicolumn{7}{c}{ Sample } \\
\cline { 2 - 7 } Parameter & $\mathrm{D} 1$ & $\mathrm{D} 2$ & $\mathrm{D} 3$ & $\mathrm{D} 4$ & $\mathrm{D} 5$ & D6 \\
\hline Free-standing length $\left(l_{b}^{a}\right)$ & 4.5 & 6.75 & 9 & 11.25 & 13.5 & 18 \\
Free-standing width $\left(w_{b}\right)$ & 9 & 9 & 9 & 9 & 9 & 9 \\
PZT thickness $\left(h_{p}\right)$ & 0.055 & 0.055 & 0.055 & 0.055 & 0.055 & 0.055 \\
Lower electrode thickness $\left(h_{e 1}\right)$ & 0.02 & 0.02 & 0.02 & 0.02 & 0.02 & 0.02 \\
Upper electrode thickness $\left(h_{e 2}\right)$ & 0.012 & 0.012 & 0.012 & 0.012 & 0.012 & 0.012 \\
Non-active layer thickness & 0.0125 & 0.0125 & 0.0125 & 0.0125 & 0.0125 & 0.0125 \\
Gap between the cantilever and the substrate & 2 & 2 & 2 & 2 & 2 & 2 \\
\hline
\end{tabular}

$l^{a}=$ Free-standing length as shown in figure 2 .

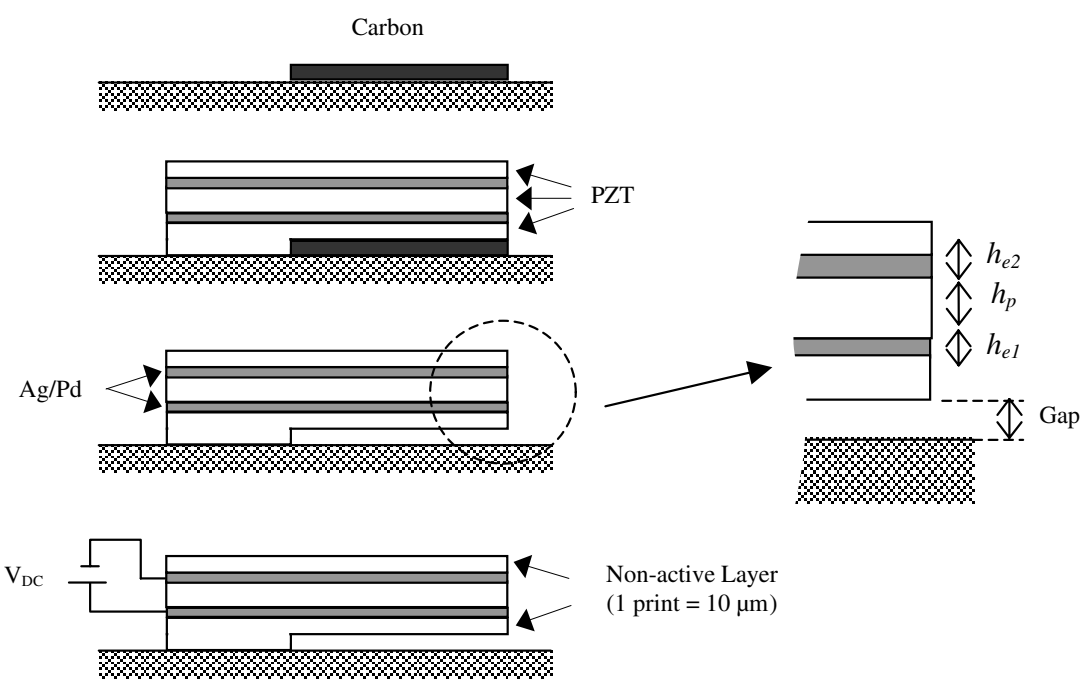

Figure 4. Fabrication steps: (1) sacrificial layer deposition, (2) sandwich layer of $\mathrm{Ag} / \mathrm{Pd}-\mathrm{PZT}-\mathrm{Ag} / \mathrm{Pd}$, (3) co-firing and burning of the sacrificial layer and (4) polarization.

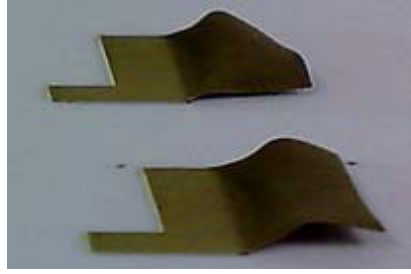

(a)

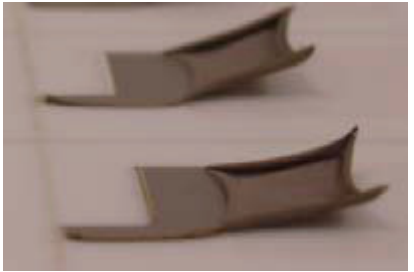

(b)

Figure 5. Photographs of free-standing structures which are $(a)$ bent inward and $(b)$ bent outward.

\section{Measurement of the piezoelectric properties of free-standing thick films}

There is no constraint on the movement and no further influence of external materials on free-standing films; therefore, the properties of the films can be determined by direct measurement similar to that used to measure bulk samples. We have used both the static and dynamic measurement methods to determine the properties of our PZT samples. A series of samples, D1-D6 as shown in figure 6, having the dimensions (measured after the fabrication process) as shown in table 1 will be used in the measurement.

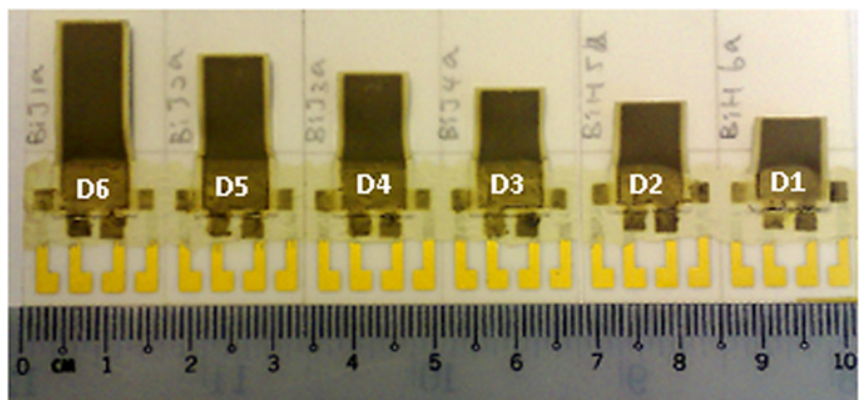

Figure 6. Photograph of free-standing cantilever samples D1-D6.

\subsection{Static measurement}

Static measurements are performed by directly applying a variable force to the piezoelectric material and measuring the charge generated. The piezoelectric charge coefficient obtained by this method (Berlincourt method) [18] is given by $d_{i j}=\frac{\text { Short circuit charge density in } i \text { direction }}{\text { Applied stress in } j \text { direction }} \frac{[\mathrm{C}]}{[\mathrm{N}]}$.

The subscript $i$ and $j$ is the notation for the poling direction and applied stress direction, respectively. The piezoelectric charge coefficient, $d_{33}$, can be measured directly with the commercial 

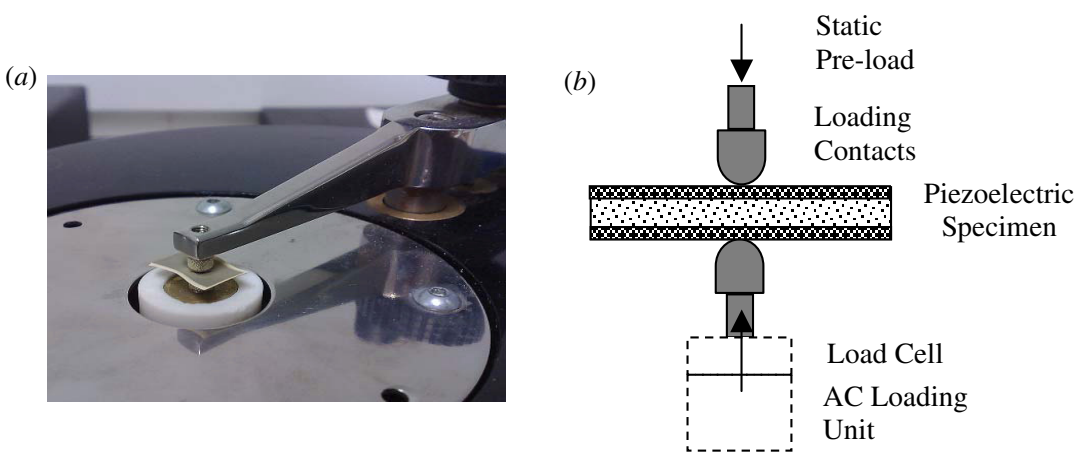

Figure 7. (a) A photograph and (b) a schematic diagram showing a piezoelectric specimen being measured by the Berlincourt measurement method.

Berlincourt piezometer system (www.piezotest.com), as shown in figure 7 . This can be used to calculate another useful parameter, the longitudinal voltage coefficient, $g_{33}$, which is related to the permittivity of the material $\varepsilon_{33}^{T}$ by

$$
g_{33}=\frac{d_{33}}{\varepsilon_{33}^{T}} .
$$

The permittivity of the material is related to the capacitance $C_{p}$ at constant (or zero) applied stress and the dimensions of the material (thickness, $h$, and area, $A$ ) as shown in equation (15). The capacitance measurements are usually carried out at $1 \mathrm{kHz}$ and at low excitation voltages (typically a few millivolts) [19]

$$
\varepsilon_{33}^{T}=\frac{C_{p} h}{A} .
$$

Two samples of PZT with different co-firing profiles were compared. The piezoelectric charge coefficient decayed as continuous varying stress was applied to the materials. This is a common phenomenon for piezoelectric materials and arises because of several factors, including the presence of a defective interface layer, which can give rise to the backswitching of domains [20]. As shown in figure 8, PZT samples co-fired at a peak temperature of $950{ }^{\circ} \mathrm{C}$ have a $d_{33}$ value of around $80 \mathrm{pC} \mathrm{N}^{-1}$ and samples co-fired at a peak temperature of $850{ }^{\circ} \mathrm{C}$ [21] have a lower value of only $50 \mathrm{pC} \mathrm{N}^{-1}$ after $8 \mathrm{~h}$ of measurement. It should be noted, however, that higher temperature processes tend to produce more cracks in the composite structures, particularly at the connecting area between the cantilever beam and the base. The cracks can prevent the free-standing structure from responding to the mechanical excitation accordingly and also cause electrical shorting between the electrodes.

\subsection{Dynamic/resonant measurement}

The resonant measurement technique is an example of a dynamic method commonly used to determine the piezoelectric and elastic properties of piezoelectrics and was first proposed by Mason and Jaffe in 1954 [22]. The technique involves the measurement of the resonant and antiresonant frequencies, which correspond to the minimum and maximum impedances of a piezoelectric material. Since these frequencies can be accurately measured, this method provides a good basis for determining the properties of bulk (or free-standing) piezoelectric materials.

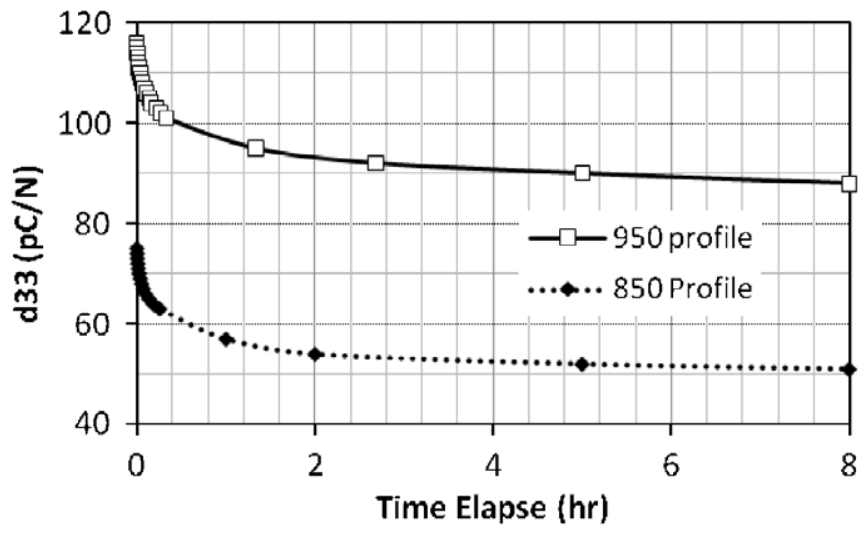

Figure 8. Piezoelectric charge coefficient $d_{33}$ decay over $8 \mathrm{~h}$ for samples with a co-fired profile at peak temperatures of $850{ }^{\circ} \mathrm{C}$ and $950{ }^{\circ} \mathrm{C}$.

As the thickness of the samples was many times smaller than their widths and lengths $(h<w / 50$ and $h<l / 100)$, this method is suitable for measuring the piezoelectric constants related to transverse modes, where the direction of polarization is perpendicular to the direction of the applied stress. The transverse piezoelectric charge coefficient is given as [22]

$$
d_{31}=\frac{1}{2 \pi f_{r}} \sqrt{\frac{\varepsilon_{33}^{T}}{\rho\left\{1+\frac{8}{\pi^{2}}\left(\frac{f_{r}}{2 \Delta f}\right)\right\}}} .
$$

This is related to the resonant frequency, $f_{r}$, the difference between resonant and antiresonant frequencies, $\Delta f$, the density, $\rho$, and the permittivity of the piezoelectric materials. The effectiveness of energy conversion between electrical and mechanical is indicated by the coupling factor, which can be determined using

$$
k_{31}=\frac{d_{31}}{\sqrt{\varepsilon_{33}^{T} s_{11}^{E}}}
$$

where $s_{11}^{E}$ is the elastic compliance at a constant electric field of the material, which can be calculated from

$$
s_{11}^{E}=\frac{1}{\rho\left(2 l_{b} f_{r}\right)^{2}} .
$$

The samples (D1-D5) with the dimensions as shown in table 1 were measured on an impedance analyser (HP 4195A), 
Table 2. Summary of measurement results for fabricated samples at standard $850{ }^{\circ} \mathrm{C}$ and $950{ }^{\circ} \mathrm{C}$ in comparison with bulk PZT from Morgan Electroceramics Ltd.

\begin{tabular}{llllll}
\hline & & & \multicolumn{2}{c}{ Co-firing profile } & \\
\cline { 3 - 5 } \multicolumn{1}{c}{ Piezoelectric constant } & & $850^{\circ} \mathrm{C}$ & $950{ }^{\circ} \mathrm{C}$ & Bulk PZT-5H [23] \\
\hline \multirow{2}{*}{ Constant electric field elastic compliance } & $s_{11}^{E}$ & $\times 10^{-12} \mathrm{~m}^{2} \mathrm{~N}^{-1}$ & 8.4 & 7.11 & 17.7 \\
Constant displacement elastic compliance & $s_{11}^{D}$ & $\times 10^{-12} \mathrm{~m}^{2} \mathrm{~N}^{-1}$ & 8.31 & 6.96 & 15.5 \\
Coupling coefficient & $k_{31}$ & Dimensionless & 0.126 & 0.145 & 0.35 \\
Relative dielectric constant & $K_{3}{ }^{T}$ & Dimensionless & 336 & 617 & 3250 \\
Piezoelectric charge coefficient & $d_{31}$ & $\times 10^{-12} \mathrm{C} \mathrm{N}^{-1}$ & -20 & -28.6 & -250 \\
& $d_{33}$ & $\times 10^{-12} \mathrm{~m}^{2} \mathrm{~N}^{-1}$ & 53 & 82 & 620 \\
Piezoelectric voltage coefficient & $g_{31}$ & $\times 10^{-12} \mathrm{~V} \mathrm{~m} \mathrm{~N}^{-1}$ & -6.73 & -5.24 & -6.7 \\
& $g_{33}$ & $\times 10^{-12} \mathrm{~V} \mathrm{~m} \mathrm{~N}^{-1}$ & 17.8 & 21.2 & 21.9 \\
Mechanical quality factor & $Q_{m}$ & Dimensionless & 130 & 98.1 & 65 \\
\hline
\end{tabular}

between $120 \mathrm{kHz}$ and $280 \mathrm{kHz}$. Usually, a thick disc-shaped bulk sample is used for measuring the piezoelectric properties from thickness vibration mode; however, longitudinal and lateral vibration modes are more significant for thin and long thick-film samples.

The lateral vibration mode was observed for samples D1 and D2 which is about $180 \mathrm{kHz}$; however, the lateral mode diminishes as the length of the sample increases which can be seen in samples D3-D5 as shown in figure 9. The resonance frequency of the longitudinal mode for sample D1 is about $240 \mathrm{kHz}$ and reduced to about $185 \mathrm{kHz}$ for sample D5. The measurement results are used to calculate the piezoelectric properties in equations (16)-(18) and other piezoelectric properties such as constant displacement elastic compliance $s_{11}^{D}$, relative dielectric constant $K_{3}^{T}$, piezoelectric voltage coefficient $g_{31}$ and mechanical quality factor $Q_{m}$ [24]. All the measurement results obtained from both the static and resonant methods are listed in table 2.

\section{Characterization of thick-film, free-standing structures}

The mechanical $Q$-factor is an important parameter that quantifies the energy dissipation through vibration. Generally, the losses can be categorized as either external or internal [25]. The external losses are due to airflow and radiation of elastic waves at the area where the cantilever was being clamped, while the internal losses are caused by surface loss and thermoelastic loss [26]. We were interested to investigate the effect of the length of the beam on the $Q$-factor of the cantilever structure. This can be used to calculate the efficiency of the structure in converting mechanical energy to electrical energy.

The total $Q$-factor, $Q_{T}$, of the structure can be determined experimentally by exciting the free-standing structures on a shaker table, as shown in figure 10, over a range of frequencies around their resonant frequency. The output was measured on a network analyzer (HP4395 A, Agilent Technologies). The shaker table was operated in a sinusoidal vibrational manner, driven by an alternating current source from an amplifier over a range of frequencies from a function generator. The acceleration of the shaker was kept at a constant level using a feedback system, where the accelerometer in the shaker measures the actual value of frequency and acceleration level and is fedback to the control processor, which generates a signal that drives the shaker. The electrical outputs (open circuit voltages and output powers) from the samples were used to measure the mechanical properties of the free-standing structures.

The efficiency of energy conversion from mechanical to electrical energy is given by [27]

$$
E_{\text {eff }}=\left(\frac{k^{2}}{1-k^{2}}\right) /\left[\frac{2}{Q_{T}}+\left(\frac{k^{2}}{1-k^{2}}\right)\right]
$$

where $k$ is the actual coupling factor $\left(<k_{31}\right)$ of the piezoelectric free-standing structure after its dielectric and mechanical losses were taken into account, which can be measured from the experiment when the optimum electrical resistive load, $R$, is known. The value is derived from [3] as

$$
k=\left[\left(\frac{2 \zeta_{T}}{R \omega_{r} C_{p}}\right)^{2}-4 \zeta_{T}^{2}\right]^{\frac{1}{4}}
$$

where $\omega_{r}$ is the angular resonant frequency, $C_{p}$ is the capacitance of the material and $\zeta_{T}$ is the total damping ratio. The damping ratio is relatively small $(<0.05)$ for the ceramic structure, and can be determined experimentally by measuring the $Q$-factor as shown below

$$
\zeta_{T}=\frac{1}{2 Q_{T}} .
$$

In a further experiment, one of the samples had a series of tungsten proof masses (of density $19.25 \mathrm{~g} \mathrm{~cm}^{-3}$ ) attached to it in order to investigate the $Q$-factor, coupling factor, the efficiency of energy conversion and the maximum stress that the structure can withstand before it fails to perform accordingly. Four different dimensions of tungsten blocks with the same thickness of $1 \mathrm{~mm}$ were used. The proof masses are denoted as M1, M2, M3 and M4, with lengths and widths as shown in figure 11 .

Stacking identical proof masses on top of the each other and adhering them with double-sided tape increases the total mass. The tape is thin, in comparison to the thickness of the proof mass and the cantilever sample. The experiment was conducted at a relatively low frequency $(\leqslant 500 \mathrm{~Hz})$ and low acceleration level $\left(\leqslant 10 \mathrm{~m} \mathrm{~s}^{-2}\right)$ such that the damping effect of the tape could be ignored. 

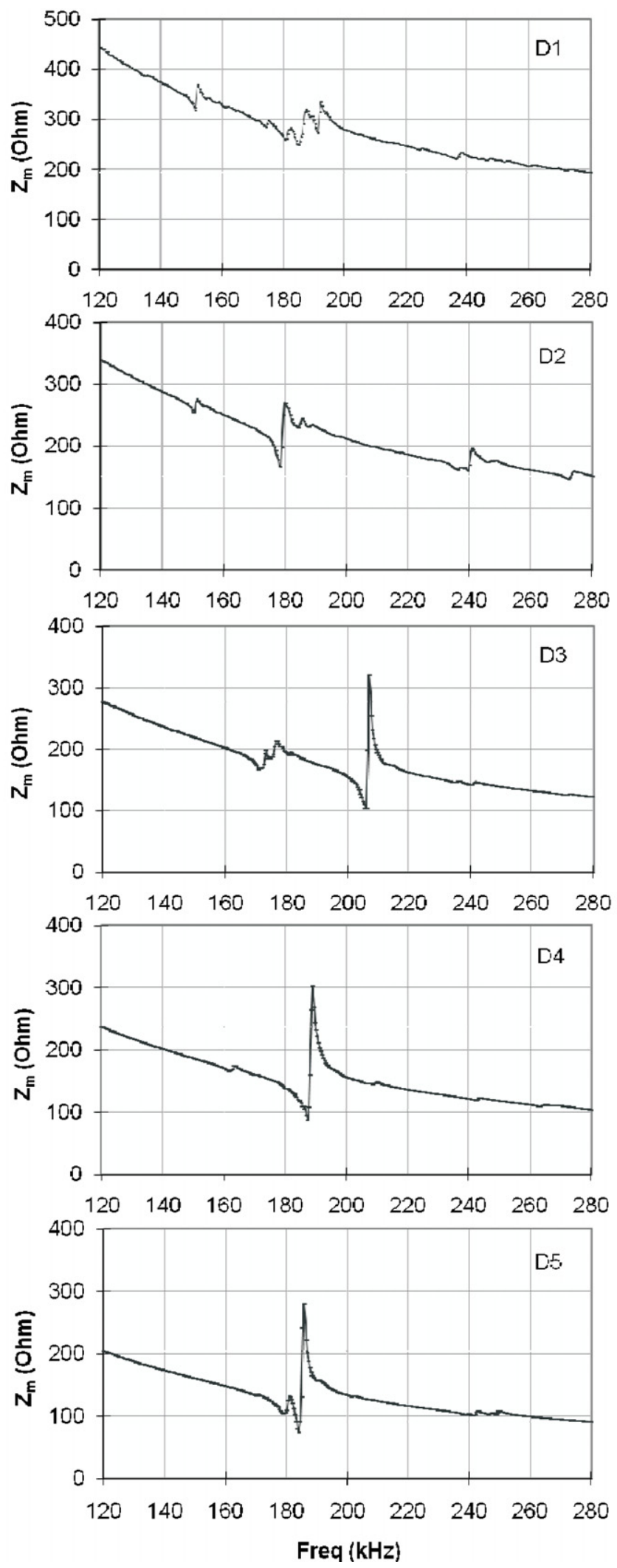

Figure 9. Electrical impedance at resonance for samples D1-D5.

\subsection{Mechanical characterization}

Figure 12(a) shows a typical frequency response for the cantilevers. Those with a length of $18 \mathrm{~mm}$ (sample D6)

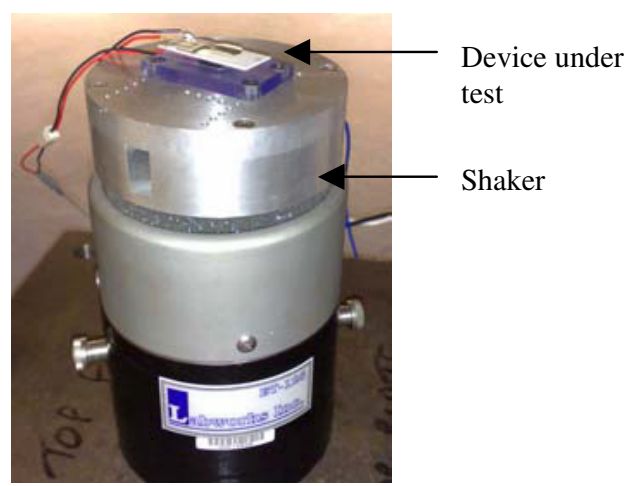

Figure 10. A piezoelectric free-standing structure under test mounted on a shaker table.

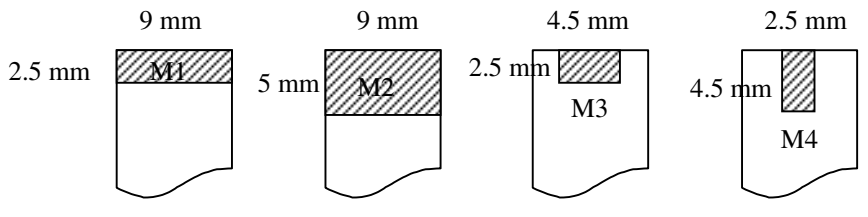

Planar view of cantilevers

Figure 11. Schematic diagram of four different proof masses M1-M4 (shaded) with the same thickness of $1 \mathrm{~mm}$ distributed on the tip of a cantilever.

have a resonant frequency of around $230 \mathrm{~Hz}$, while shorter cantilevers, with a length of $4.5 \mathrm{~mm}$, have a resonant frequency of about $2300 \mathrm{~Hz}$.

Attaching additional proof masses to the cantilever beam can further reduce the resonant frequency. As an example, the natural frequency of sample D5 is reduced to $68 \mathrm{~Hz}$ with proof masses of $2.22 \mathrm{~g}$, as shown in figure 12(b). The measurement results also show that the natural frequency of the structure is not affected by the distribution of the proof masses.

Figure 13 shows that the $Q_{T}$ of the samples is in the range 120-215. Sample D3, which is roughly a square shape, has a maximum value of $Q_{T}$ of 215. A shorter or longer cantilever does not appear to exhibit the same $Q$-factors as those having a square structure. This is because shorter or longer cantilever structures suffer losses at different rates and with different dominant factors. The energy dissipation losses at the support is dominant for a shorter structure [28], while air-damping losses become dominant for longer cantilever structures [29]. With the measured $Q$-factor value, the total damping ratio for the samples was calculated to be in the range of $0.002-$ 0.005 .

The $Q$-factor of sample D5 was reduced from about 185 to about 30 , but the coupling factor, $k$, increased from 0.06 to 0.2 when a proof mass of $2.2 \mathrm{~g}$ was attached. This shows that more energy is stored in the structure at resonance [30], and hence more electrical energy can be extracted with improved energy conversion efficiency as demonstrated in equation (19), which is in good agreement with experimental results shown in figure 14(b). Figure 14(a), on the other hand, shows that the efficiency decreases with increasing cantilever length. The shortest cantilever sample appears to have a saturation level of efficiency at about $35 \%$. Sample D5 has an efficiency of $25 \%$, 


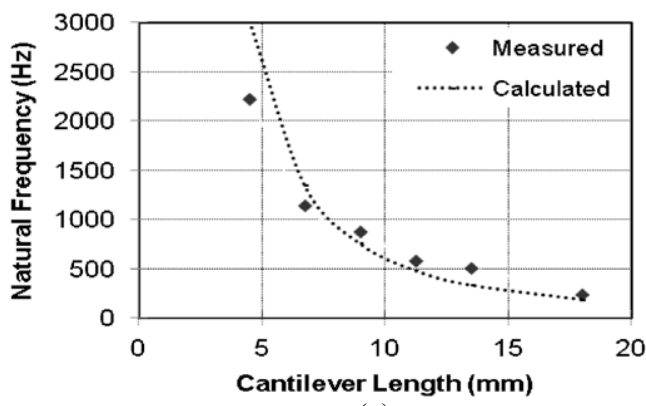

(a)

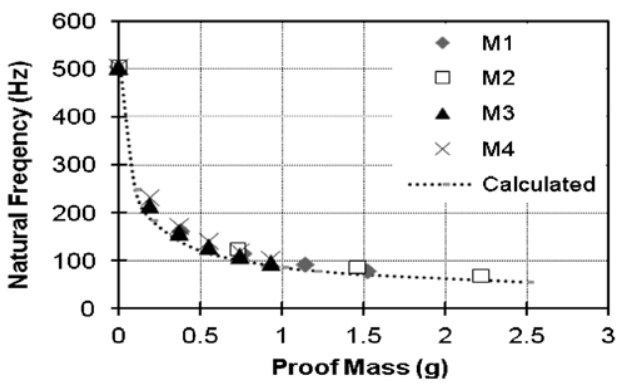

(b)

Figure 12. Experimental results in agreement with theoretical calculation of resonant frequency as a function of $(a)$ the cantilever lengths and $(b)$ mass for sample D5 with length $13.5 \mathrm{~mm}$.

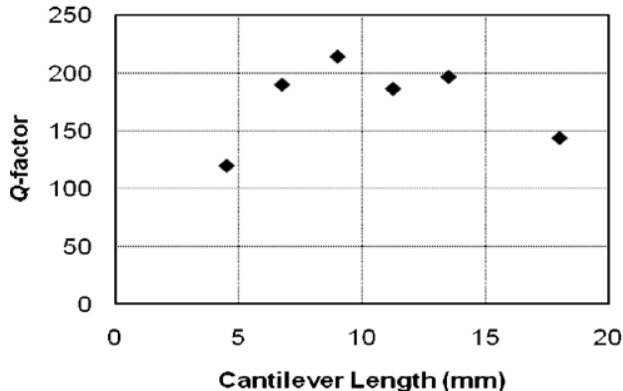

(a)

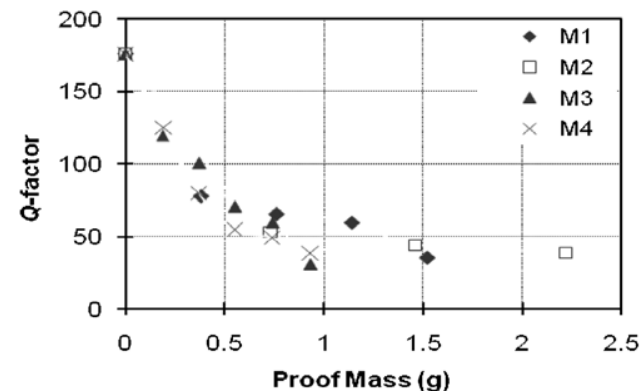

(b)

Figure 13. $Q_{T}$ as a function of $(a)$ cantilever length and $(b)$ mass for sample D5 for four different mass distributions.

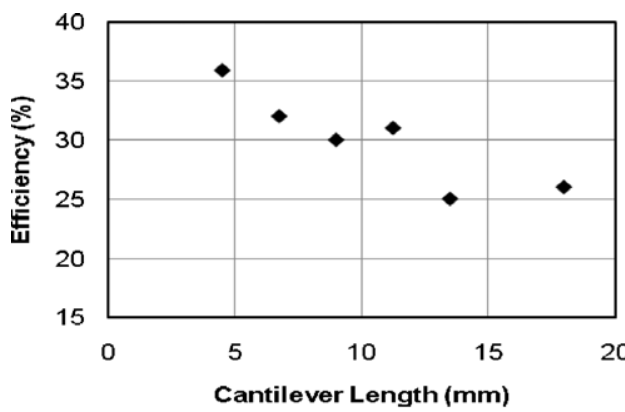

(a)

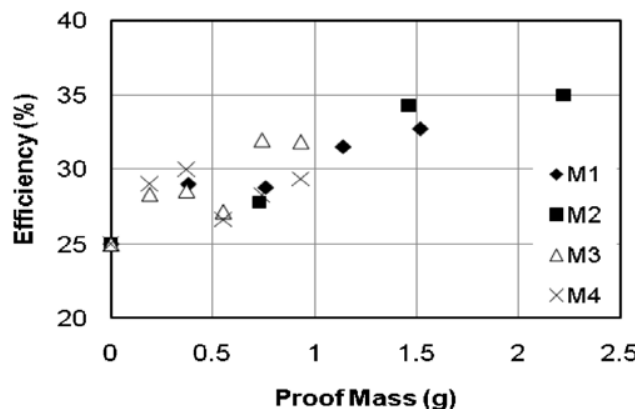

(b)

Figure 14. The energy conversion efficiency as a function of $(a)$ cantilever length and $(b)$ mass for sample D5.

which increases to around $35 \%$ with the addition of a $2.2 \mathrm{~g}$ proof mass. There is, of course, a limit for the value of the proof mass, as there is a maximum stress that can occur before the free-standing structure will fracture, this was determined experimentally to be $8.5 \mathrm{MPa}$.

\subsection{Evaluation of electrical output}

The same series of samples was used to investigate the electrical output performance from the piezoelectric cantilever structures. A modest electrical power output (a few nanowatts) was produced when the composite unimorph structure was operated in its bending mode. The output power is affected by the distance from the centroid of the piezoelectric material layer to the neutral axis of the composite cantilever, $d$. The samples used in the experiment have a $d$ value of $6 \mu \mathrm{m}$, which was calculated from equation (3) by using the parameters shown in table 1 and with the assumption that the elastic moduli for the $\mathrm{Ag} / \mathrm{Pd}$ electrode and PZT layer are $116 \mathrm{GPa}$ and $60 \mathrm{GPa}$, respectively.

The electrical output power from the devices was measured by connecting the lower and upper electrodes to a programmable load resistance and then converting the voltage into a digital signal to be measured with a National Instruments Sequence Test programme. A series of different experiments was carried out to investigate the output power as a function of cantilever length, electrical load resistance, proof mass and input acceleration level.

By careful selection of resistive loads, the electrically induced damping can be adjusted so that it is equal to mechanical damping. Once the optimal resistive load is obtained, the maximum output power is produced. Figure 15 shows the experimental and calculated results for samples D6 and D5 when excited to their resonant frequencies 


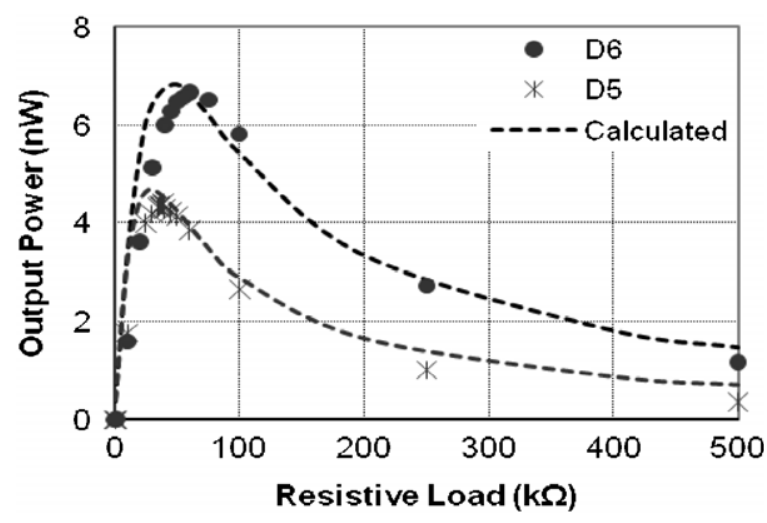

Figure 15. Output power at resonant frequency as a function of electrical resistive load when accelerated at a level of $100 \mathrm{milli}$ ' $g$ ' $\left(\approx 1 \mathrm{~m} \mathrm{~s}^{-2}\right)$.

at an acceleration level of 100 milli ' $g$ ' $\left(\approx 1 \mathrm{~m} \mathrm{~s}^{-2}\right)$. The optimum output power is obtained by driving into resistive loads of $60 \mathrm{k} \Omega$ and $39 \mathrm{k} \Omega$, respectively.

The required value for the resistive load was found to be a function of the length of the cantilever, as shown in figure $16(a)$. It is further increased when proof masses are attached, as shown in figure $16(b)$. The optimum resistive load for sample D5 saturates at around $250 \mathrm{k} \Omega$, with an added proof mass exceeding $1.5 \mathrm{~g}$. The distribution of the masses does not seem to influence the value of the optimum resistive load.

The distribution of the proof masses, however, has a significant influence on the output power, as shown in figure $17(b)$. Sample D5 with attached proof masses of dimensions M1 produces a maximum output power of about $40 \mathrm{nW}$, which is more than a factor of 8 higher than a device without the proof mass. M1 has a distribution of masses focused at the tip of the cantilever and appears to have imposed the maximum allowable stress on the cantilever, before a reduction of power due to energy losses from mechanical damping at greater values of added mass $(>1.2 \mathrm{~g})$. Proof masses having broader distribution areas on cantilever M2 can increase beyond this before mechanical damping becomes dominant. The larger mass of M2, however, does not show a significant improvement in the output power, and furthermore, it is not desirable to stress the fragile ceramic cantilever beyond 8.5 $\mathrm{MPa}$ (experimental maximum stress point). In this case, an acceleration level of $1 \mathrm{~m} \mathrm{~s}^{-2}$ allows a maximum mass of around $2.8 \mathrm{~g}$. M3 and M4, respectively, have a mass distribution towards the centre spine of the cantilever and show inferior output power levels of less than a quarter the value of the maximum power stored in the piezoelectric materials.

The output power increases with the cantilever length as shown in figure 17(a). The improvement is not as effective as adding additional proof masses. In order to keep the overall device size as small as possible, the latter is therefore the preferred method for improvement in the power output.

In another experiment, sample D6 was examined to study the output power levels when it was excited over a range of frequencies around its resonant frequency and at different acceleration levels. Figure 18 shows that the output power increases with the acceleration level as expected, but the resonant frequency drops as the acceleration level increases. At an acceleration of 100 milli ' $g$ ' $\left(\approx 1 \mathrm{~m} \mathrm{~s}^{-2}\right)$, the sample produced an output power of $10.2 \mathrm{nW}$ at a resonant frequency of $235 \mathrm{~Hz}$. The output power increased to $84 \mathrm{nW}$ when the sample was excited to an acceleration level of 1 ' $g$ ' $\left(\approx 10 \mathrm{~m} \mathrm{~s}^{-2}\right)$ at the same frequency. However, by shifting to a new resonant frequency of $229 \mathrm{~Hz}$, the output power increased to $280 \mathrm{nW}$.

We can conclude that the use of a proof mass and input acceleration levels are the important factors in improving the electrical output from resonant structures in addition to increasing the length of the cantilevers. The distance from the centroid of the active piezoelectric layer to the neutral axis of the composite cantilever is also an important factor in determining the electrical output, which can be implemented in a form of multimorph structure.

\section{Electrical output improvement}

Multimorph structures were fabricated using a co-firing profile of $950^{\circ} \mathrm{C}$. They comprise three laminar sections of PZT having equal thicknesses of about $40 \mu \mathrm{m}$ and physically separated by thin layers of $\mathrm{Ag} / \mathrm{Pd}$ electrodes of equal thickness $(12 \mu \mathrm{m})$ as shown in figure 19. Using the same fabrication method

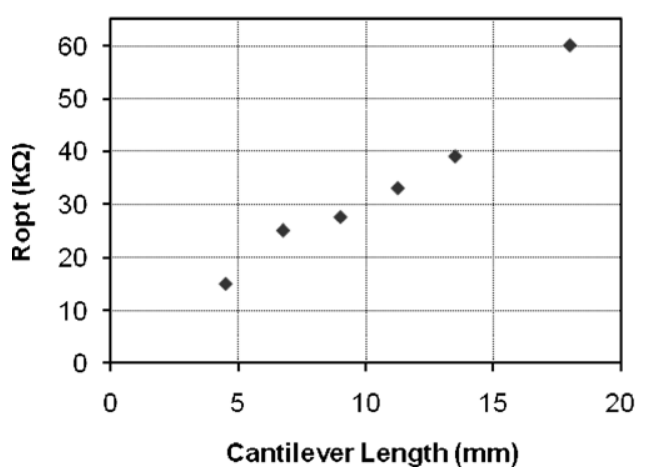

(a)

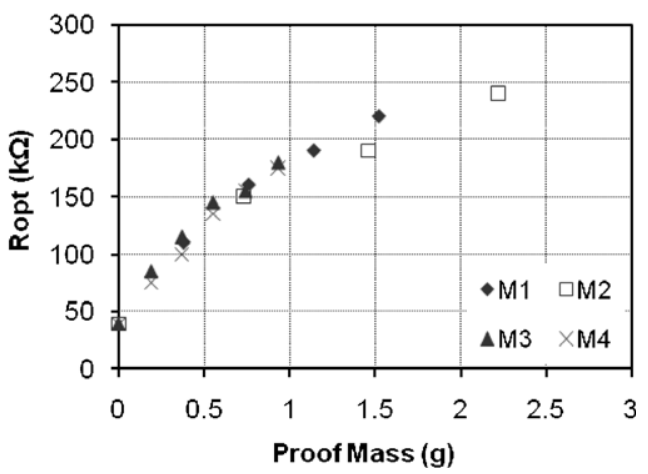

(b)

Figure 16. Optimum resistive load, $R_{\mathrm{opt}}$, as a function of ( $a$ ) cantilever length and (b) mass for sample D5. 


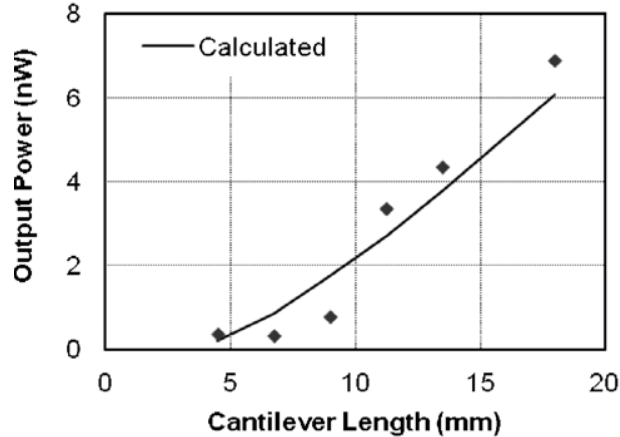

(a)

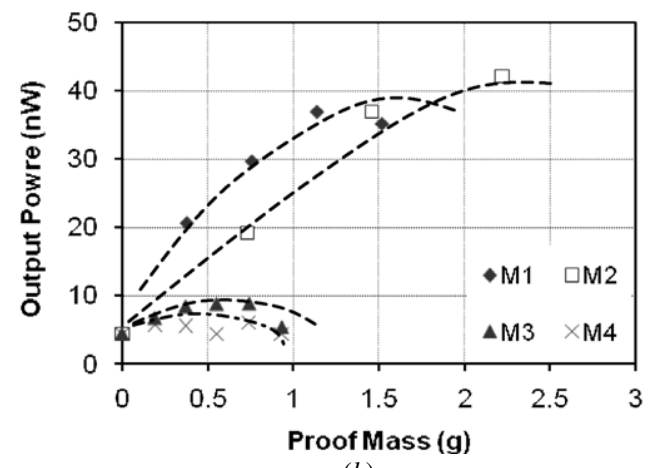

(b)

Figure 17. Output power at optimum resistive load as a function of $(a)$ cantilever length and $(b)$ mass for sample D5 loaded with different distributions of proof masses. (The dotted line is a guide to show the pattern of the change.)

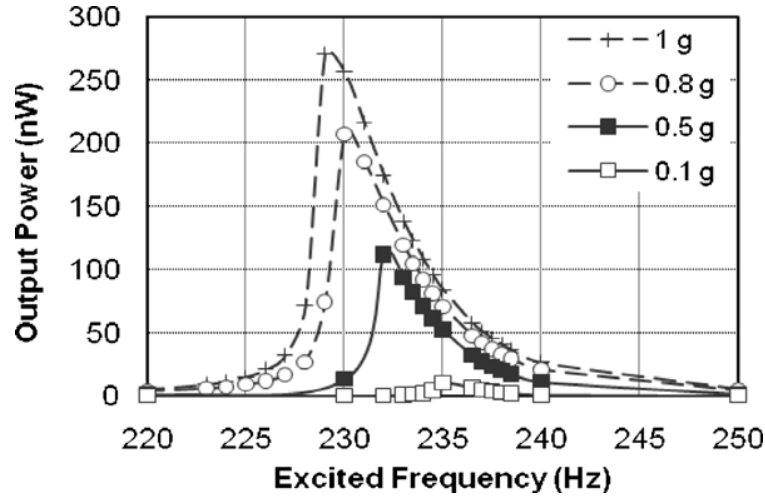

Figure 18. Output power as a function of excited frequency at different levels of acceleration for sample D6 ( $1^{\prime} g$ ' $\left.\approx 10 \mathrm{~m} \mathrm{~s}^{-2}\right)$.

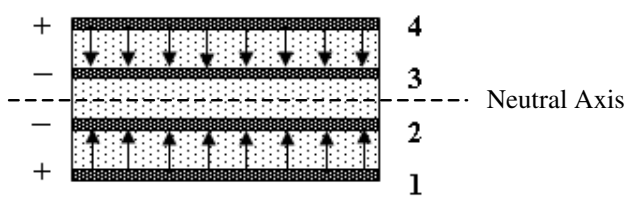

Figure 19. Cross-sectional view of a multimorph structure. The number beside each layer denotes the fabrication sequence of electrode plates.

as used for the unimorph structures, the upper and lower electrodes of the composite multimorph cantilevers were also covered with a thin layer of PZT, with a thickness of $10 \mu \mathrm{m}$. Since the lower and upper layers of piezoceramic are displaced further from the neutral axis, a significant improvement in the electrical output (as predicted from equation (11)) is expected.

A multimorph sample having a total thickness of $168 \mu \mathrm{m}$ and a length of $18 \mathrm{~mm}$ was used to investigate the electrical output performance. The multimorph structure was polarized at $220 \mathrm{~V}$ in series by connecting the outer electrodes to the positive terminal and the inner electrodes to the negative terminal of the dc power source, at a temperature of $200{ }^{\circ} \mathrm{C}$ for $30 \mathrm{~min}$. The outer electrode plates were polarized in the same direction towards the centre plates, and this produced a neutral polarity at the centre piezoelectric layer, which is also served as a mechanical neutral axis to the structure. This central layer

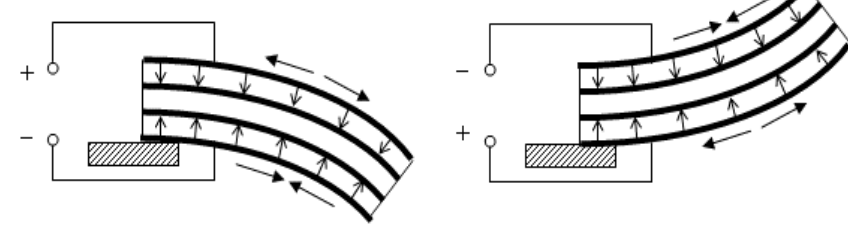

Figure 20. A diagram showing downward and upward bending positions of a multimorph cantilever, which produces an alternating output voltage at the output terminal.

is not similar to the traditional supporting platform because it is electro-active and therefore has the potential to produce an electrical output when a correct configuration of electrode terminals is in place.

When the cantilever resonates, as shown in figure 20, an alternating voltage is produced. At a point where the cantilever bends downwards, tensile forces on the upper piezoelectric element (perpendicular to the direction of polarization) generate voltages of the same polarity as the poling voltage. The compressive forces on the lower piezoelectric element generate a voltage of opposite polarity to that of the poling voltage and vice versa, when the cantilever is bent upwards.

The open circuit voltages across a few combinations of electrodes were investigated. Ideally, the open circuit voltages across terminals 3 and 4 (upper section of PZT) and terminals 1 and 2 (lower section of PZT) are similar, but experimentally there is a discrepancy in the output voltage between the upper and lower sections of PZT. This is because the neutral axis is not precisely coincident with the centroid of the PZT layers. PZT sections with larger $d$ (distance from the neutral axis to the centroid of the PZT layer) produce greater output voltages.

The open-circuit voltage across terminals 1 and 4 , with a short between the two centre electrodes 2 and 3, is equivalent to a series connection of two piezoelectric impedance components and produces a total voltage that is equal to the sum of the individual lower and upper sections of the PZT. An open-circuit voltage exceeding $2.5 \mathrm{~V}$ was measured at a resonant frequency of $400 \mathrm{~Hz}$ when driven at an acceleration level of 1.5 ' $g$ ' $\left(\approx 15 \mathrm{~m} \mathrm{~s}^{-2}\right)$, as shown in figure 21 . An equivalent circuit of parallel connection is produced when a positive terminal (made by connecting electrodes 1 and 4), and 


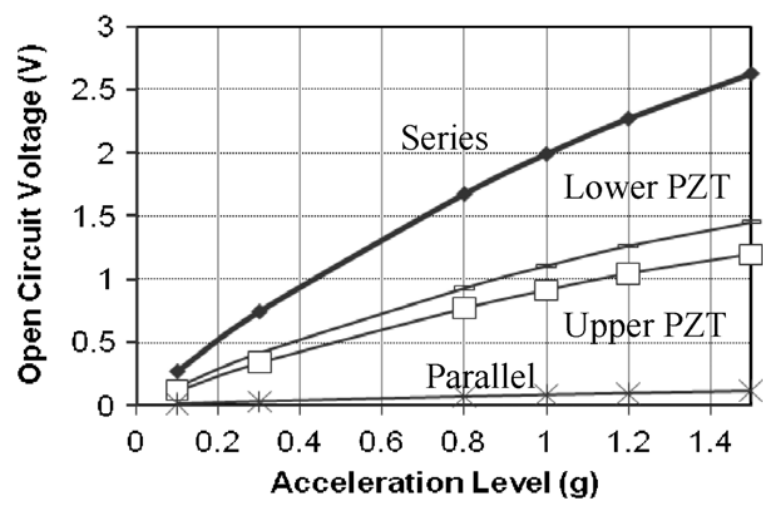

Figure 21. Open circuit voltage as a function of the acceleration level for a multimorph cantilever with different electrode configurations.

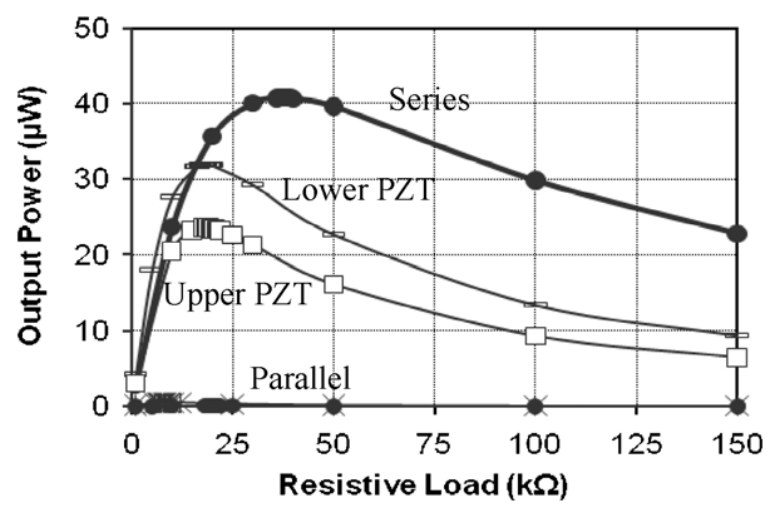

Figure 22. Output power as a function of resistive load for a multimorph cantilever with a few different electrode configurations.

negative terminal (made by connecting the central electrodes 2 and 3 ) are measured.

Maximum output power can be obtained by loading the multimorph structure with a range of resistances at its resonance frequency as shown in figure 22. The upper and lower sections of the PZT produce a maximum output power of $25 \mu \mathrm{W}$ and $33 \mu \mathrm{W}$, respectively, when driving similar resistive load at $18.5 \mathrm{k} \Omega$, at an acceleration level of $0.5 \mathrm{~g}$. The output power is scaled up when connecting the individual lower and upper sections to make a series configuration and this produced a maximum power of about $40 \mu \mathrm{W}$, when driving a greater resistive load of $37.5 \mathrm{k} \Omega$. The magnitude of the output power is significantly improved by a factor of about 400 compared to a unimorph composite structure of similar length.

\section{Conclusions}

Piezoelectric thick-film free-standing structures in the form of cantilevers were fabricated with a combination of conventional thick-film technology and sacrificial layer techniques. The structures were characterized in order to investigate their mechanical and electrical properties. Free-standing structures offer several advantages over those fabricated onto inert substrates. One of these is that the piezoelectric material can be characterized using direct static measurement (Berlincourt) methods and resonant measurement techniques, which cannot be used to measure thick-films fabricated onto substrates. The ceramic free-standing cantilevers, having lengths between 4.5 $\mathrm{mm}$ and $18 \mathrm{~mm}$, were found to have $Q$-factors in the range 100 and 200, and those having square dimensions produced the highest Q-factors, but these gradually reduced with an increasing length because of air-damping effects. The energy conversion efficiency, however, was found to increase up to $35 \%$ by attaching a tungsten proof mass at the tip of the cantilevers. The output power is also increased when the cantilevers were loaded with proof mass up to the point at which mechanical damping becomes dominant. A distribution of masses covering the width of the beam and focused towards the tip of the cantilever was found to impose maximum stress on the piezoelectric materials, and hence maximum output power. Electrical output is significantly improved by increasing the distance between the PZT layer and the neutral axis, which was shown experimentally with multimorph composite cantilevers. The output power increases by a factor of around 400 compared to the unimorph structure, when each layer of PZT is connected in series. Further research is underway to develop a compact, efficient thickfilm piezoelectric device, which is capable of integration into micro-energy harvesting systems.

\section{Acknowledgment}

A PhD scholarship from Universiti Teknikal Malaysia Melaka is gratefully acknowledged.

\section{References}

[1] Glynne-Jones P, Beeby S P and White N M 2001 Towards a piezoelectric vibration-powered microgenerator IEE Proc. Sci. Meas. Technol. 148 68-72

[2] Roundy S, Wright P K and Rabaey J 2003 A study of low level vibrations as a power sources for wireless sensor nodes Comput. Commun. 26 1131-44

[3] Roundy S and Wright P K 2004 A piezoelectric vibration based generator for wireless electronics Smart Mater. Struct. 12 1131-42

[4] Sodano H A, Inman D J and Park G 2005 Comparison of piezoelectric energy harvesting devices for recharging batteries J. Mater. Sci., Mater. Electron. 16 799-807

[5] Jeon Y B, Sood R, Jeong J and Kim S-G 2005 MEMS power generator with transverse mode thin film PZT Sensors Actuators A 122 16-22

[6] Itoh T and Suga T 1996 Self-excited force-sensing microcantilevers with piezoelectric thin films for dynamic scanning force microscopy Sensors Actuators A 54 477-81

[7] Yi J W, Shih W Y and Shih W H 2002 Effect of length, width, and mode on the mass detection sensitivity of piezoelectric unimorph cantilevers J. Appl. Phys. 91 1680-6

[8] Lu J, Ikehara T, Zhang Y, Mihara T, Itoh T and Maeda R 2008 High quality factor silicon cantilever driven by PZT actuator for resonant based mass detection Proc. Design, Test, Integration \& Packaging of MEMS/MOEMS (DTIP) (Nice, France, 9-11 April 2008)

[9] White N M and Turner J D 1997 Thick-film sensors: past, present and future Meas. Sci. Technol. 8 1-20

[10] Steinhausen R et al 1998 Clamping of piezoelectric thin films on metallic substrates: influence on the effective piezoelectric modulus $d_{33}$ Proc. 11th IEEE Int. Symp. on Application of Ferroelectrics, ISAF (Montreux, Switzerland, 24-27 August 1998) 
[11] Torah R N, Beeby S P and White N M 2004 Experimental investigation into the effect of substrate clamping on the piezoelectric behaviour of thick-film PZT elements J. Phys. D: Appl. Phys. 37 1074-8

[12] Stecher G 1987 Free supporting structures in thick-film technology: a substrate integrated pressure sensor Proc. 6th European Microelectronics Conf., Bournemouth pp 421-7

[13] Gere J M 2001 Mechanics of Materials 5th edn (Pacific Grove, CA: Brooks/Cole)

[14] Merhaut J 1981 Theory of Electroacoustics (New York: McGraw-Hill)

[15] Li X, Shih W Y, Aksay I A and Shih W-H 1999 Electromechanical behaviour of PZT-brass unimorphs J. Am. Ceram. Soc. 82 1733-40

[16] Kok S-L, White N M and Harris N R 2008 Free-standing thick-film piezoelectric device Electron. Lett. 44 280-1

[17] Birol H, Maeder T and Ryser P 2007 Application of graphite-based sacrificial layers for fabrication of LTCC (low temperature co-fired ceramic) membranes and micro-channels J. Micromech. Microeng. 17 50-60

[18] Berlincourt D, Curran D R and Jaffe H 1964 Piezoelectric and piezomagnetic material and their function in transducers Phys. Acoust. 1 169-270

[19] Jordan T, Ounaies Z, Tripp J and Tcheng P 1999 Electrical properties and power considerations of a piezoelectric actuator Proc. Material Research Society Symp. (December 1999) pp 203-8

[20] Shepard J F Jr, Chu F, Kanno I and Trolier-McKinstry S 1999 Characterization and aging response of the $d_{31}$ piezoelectric coefficient of lead zirconate titanate thin films J. Appl. Phys. 85 6711-6
[21] Torah R N, Beeby S P and White N M 2004 Improving the piezoelectric properties of thick-film PZT: the influence of paste composition, powder milling process and electrode material Sensors Actuators A 110 378-84

[22] Mason W P and Jaffe H 1954 Methods for measuring piezoelectric, elastic, and dielectric coefficients of crystals and ceramics Proc. IRE 42 921-30

[23] Morgan Electroceramics 2007 Piezoelectric Ceramics: Electro ceramic solutions www.morganelectroceramics.com/ pdfs/piezo-web\%20pdf.pdf

[24] Jordan T L and Ounaies Z 2001 Piezoelectric ceramics characterization. NASA/CR-2001-211225 ICASE Report No 2001-28

[25] Jinling Y, Ono T and Esashi M 2002 Energy dissipation in submicrometer thick single-crystal silicon cantilevers J. Microelectromech. Syst. $11775-83$

[26] Sandberg R, Lhave K, Boisen A and Svendsen W 2005 Effect of gold coating on the Q-factor of a resonant cantilever J. Micromech. Microeng. 15 2249-53

[27] Richards C D, Anderson M J, Bahr D F and Richards R F 2004 Efficiency of energy conversion for devices containing a piezoelectric component J. Micromech. Microeng. $14717-21$

[28] Yasumura K Y et al 2000 Quality factors in micron- and submicron-thick cantilevers J. Microelectromech. Syst. 9 117-25

[29] Nouira H, Foltete E, Hirsinger L and Ballandras S 2007 Investigation of the effects of air on the dynamic behaviour of a small cantilever beam J. Sound Vib. 305 243-60

[30] Choi W, Jeon Y, Jeong J H, Sood R and Kim S 2006 Energy harvesting MEMS device based on thin film piezoelectric cantilevers J. Electroceram. 17 543-8 